International Journal of Education (IJE) Vol.6, No.4, December 2018

\title{
EFFECTS OF CORRECTIVE FEEDBACK ON LEARNERS OF ENGLISH AS A SECOND LANGUAGE (ESL)
}

\author{
Gelan Hesham Abdou Ahmed Mahmoud \\ Zewail University of Science and Technology,Egypt
}

\begin{abstract}
This paper attempts to probe the effects of corrective feedback on English as Second Language (ESL) students' motivation, achievement and performance. After reviewing seven theses and twenty-seven research papers, it has been noticed that corrective feedback has exhibited remarkable effectiveness in boosting learners' motivation, achievement and performance when learning second languages. However, other research underscored that corrective feedback impinges learners' performance and motivation negatively. Hence, further research needs to be conducted to probe the effectiveness of corrective feedback when incorporated in other foreign languages, and various subject matters.
\end{abstract}

\section{KEYWORDS}

Corrective Feedback, Language Acquisition, ESL Learners' Motivation, Performance, Achievement

\section{INTRODUCTION}

The United Nations (UN) set 17 Sustainable Development Goals in 2015 to eliminate poverty and create a life of dignity worldwide. One of these goals aims at ensuring quality education to all pupils, regardless of their race or economic background (UNESCO, 2016). In fact, one of the pivotal factors for achieving such goal is by providing pupils with constructive feedback (Owen, 2016). To elaborate, feedback is deemed as pieces of information provided by agents concerning one's comprehension and understanding (Hattie \& Timperley, 2007). In addition to Hattie and Timperley's interpretation of feedback, Sadler (1989) regarded feedback as a process, in which agents provide accurate information about the outcomes of assessments or learning tasks in an attempt to bridge the gap between what is grasped and what is aimed to be understood in classes. Hence, it can be concluded from Sadler's interpretation that feedback entails two crucial levels. First, feedback, which is either a task or assessment oriented, entails directions for students to gather more comprehensive information. Second, feedback notably targets students' information processing strategies, which help them to reorganize, and amend their comprehension of notions. Furthermore, recent researches have documented the worthwhile advantages of feedback; feedback empowers students to adopt strategies to adjust their comprehension, develop competence and autonomy, challenge their understanding of terms, monitor their metacognitive processes, set learning goals, spot misconception, collect information to solve issues, acquire error detection skills and improve their self-regulatory skills (Pirhonen, 2016; Gedye, 2010; Horbacauskiene \& Kasperaviciene, 2015; Sadler, 1989). Hence, the purpose of this paper is to DOI : 10.5121/ije.2018.6405 
International Journal of Education (IJE) Vol.6, No.4, December 2018

shed light on a well-researched type of feedback which is corrective feedback. This paper encompasses four, fundamental sections, which are research questions, literature review, gap, and recommendations.

\section{Research Questions}

This paper attempts to address the research question: What are the impacts of corrective feedback on ESL learners? In addition, below are the sub-research questions, which the paper seeks to answer:

Q1: What are the impacts of corrective feedback on ESL learners' motivation?

Q2: What are the impacts of corrective feedback on ESL learners' achievement?

Q3: What are the impacts of corrective feedback on ESL learners' performance?

\section{Literature Review}

This section is divided into fundamental subsections: corrective feedback, language acquisition, motivation, achievement, and performance.

\section{Corrective Feedback}

It is regarded as a process in which teachers provide their students with feedback in terms of syntactic and lexical complexity, grammar and sentence structure (Chu, 2011). Yet, Chomsky highlighted that such type of feedback is worthless, because of the existence of a universal grammar system in human beings (Owen, 2016; Pirhonen, 2016). Moreover, corrective feedback has two, main forms: selective and comprehensive. In the selective form, teachers are inclined to detect a limited number of mistakes in regards to vocabulary and grammar (Boudraa, 2016; Chu, 2011). Such form "saves time for the language teacher, and allows the students to recognize patterns of errors" (Horbacauskiene \& Kasperaviciene, 2015, p. 3). When spotting a limited number of mistakes, teachers are developing students' editing skills in order to reinforce and boost their language acquisition (Mezhoud, 2015). In contrast to the selective form, tutors, in the comprehensive form, detect all the mistakes in terms of grammar, sentence structure, and lexical and syntactic complexity (Choi, 2013; Mezhoud, 2015). Besides, corrective feedback comprises of six, major categories, which are: explicit, recast, explanation, metalinguistic, elicitation, and repetition (Boudraa, 2016; Chu, 2011). Firstly, explicit correction occurs when teachers spot and correct students' errors. Secondly, recasts "refer notably to the formulation of all or part of the student's utterances, except for the mistake" (Boudraa, 2016, p. 16). Thirdly, explanations are provided to students to thoroughly address their misconceptions of concepts, and terms. Fourthly, metalinguistic feedback is the incorporation of comments, or questions to enable students to detect, and correct their mistakes. Fifthly, elicitation is used by teachers to directly get the correct forms from students. Lastly, repetition is employed by teachers when they repeat students' mistakes using higher intonations to help them spot their errors (Choi, 2013; Mezhoud, 2015; Boudraa, 2016; Chu, 2011; Owen, 2016; Horbacauskiene \& Kasperaviciene, 2015). Finally, corrective feedback is a fundamental facet in the teaching and learning processes. 
International Journal of Education (IJE) Vol.6, No.4, December 2018

\section{Language Acquisition}

It is the process of learning a second language (Kuhl, 2004). In order to precisely comprehend the process of language acquisition, three pivotal theories must be elaborated. First of all, creative construction theory emphasizes the fact that people possess an innate language system which reinforces the acquisition of any foreign language. Such a theory rests on two, fundamental elements: organizer, and monitor. To begin, the former highlights how learners organize their language system. Besides, the latter focuses on how learners detect and correct their errors (Engin, 2009). Second of all, communicative language teaching accentuates on learners' abilities to communicate using the target language in classrooms. Thus, teachers are obligated to employ meaningful activities, which entice learners to practice the target language (Kuhl, 2004). Lastly, cognitive approach theory sheds light on learners' recollection of the target language, once they have been minutely exposed to it (Stefansson, 2013). In addition to language acquisition theories, there are important stages that learners go through when acquiring a second language (Nikolov \& Djigunovic, 2006). To start, pre-production occurs when learners are expanding their vocabulary without speaking the target language. Next, early production happens when learners are able to create short sentences, which are not completely correct. Then, speech emergence takes place when learners engage in straightforward, short conversations (Kuhl, 2004). Afterwards, intermediate stage is witnessed when learners begin to construct more complex, elaborate sentences. Lastly, advanced stage is reached when learners become native-like (Engin, 2009). In conclusion, various theories have been developed to comprehend the process of language acquisition.

\section{Corrective Feedback and Motivation}

Corrective feedback has been documented to increase students' motivation and enthusiasm (Hyland \& Lo, 2007; Simpson, 2006; Gardner, 2011; Choi, 2013; Chu, 2011; Sermsook, Othman, Liamnimitr, \& Pochak, 2017). For instance, a study, which investigated the effects of corrective feedback on students' motivation, and enthusiasm to produce better writing, was launched in a school in Thailand. This study entailed thirty four students who were studying English (Hamidun, Hashim, \& Othman, 2012). Throughout the semester, the teacher provided students with individualized, corrective feedback after any writing assessment. When the academic semester came to an end, the researchers interviewed the participants to probe the impacts of corrective feedback on their motivation. After analyzing the data, the researchers stressed that the students were highly motivated, thanks to corrective feedback, to write in English and produce coherent essays.

Moreover, a study attempted to investigate the impacts of corrective feedback on students' motivation and enthusiasm (Mezhoud, 2015). This study, which was initiated in Algeria, entailed eighty students. Similar to the previous study, teachers provided individualized, corrective feedback after formative assessments to learners. At the end of the semester, the researcher administered a thirty item Likert-scale questionnaire to the participants. After analyzing the data, Mezhoud stressed that $87 \%$ of the pupils were excited to receive feedback from their teachers, $84 \%$ were not anxious towards their teachers' feedback, $80 \%$ were not upset when receiving feedback from their teachers, $90 \%$ were not ashamed when being provided with feedback, $10 \%$ were unwilling to receive feedback, $90 \%$ were pleased with corrective feedback, $90 \%$ esteemed 
International Journal of Education (IJE) Vol.6, No.4, December 2018

their teachers' correction of mistakes and 98\% appreciated corrective feedback. Thus, students' enthusiasm and motivation skyrocketed when teachers provided them with corrective feedback.

Besides, a study, which was launched in Algeria, investigated the effects of corrective feedback on pupils' motivation (Leyla, 2016). Also, forty-two students participated in such study. Similar to the above studies, teachers provided students with individualized, corrective feedback after formative assessments. After the academic semester of 2015, Leyla interviewed the participants to probe the impacts of corrective feedback on students' motivation. After analyzing the data, he evinced that the majority of the students were hugely motivated to produce better writings, thanks to corrective feedback. So, it can be concluded that such type of feedback sparks students' motivation to better perform in language acquisition.

In contrast to the above studies, El Saghayer (2014) highlighted the fact that corrective feedback impinges learners' motivation negatively. To elaborate, he launched a study at two secondary schools in Libya so as to investigate the impact of corrective feedback on learners' motivation. Furthermore, he randomly picked one hundred students, who voluntarily participated in such a study. At the end of the academic semester of 2013, he administered an eleven item Likert-scale questionnaire to the students. Having analyzed the data, he reported that $50 \%$ of the students learnt a lot from corrective feedback, 55\% appreciated their teachers' efforts in providing them with feedback, $19 \%$ felt afraid when their teachers corrected their mistakes, $10 \%$ despised being corrected by their teachers, $65 \%$ admitted being demotivated when teachers corrected their mistakes, $45 \%$ were frightened of committing mistakes, $52 \%$ comprehended the reasons of making errors, $35 \%$ indicated being pleased when teachers corrected their mistakes, $40 \%$ revealed being upset when they did not understand their teachers' feedback and $90 \%$ confessed receiving immediate feedback. To sum up, corrective feedback has demonstrated ineffectiveness in skyrocketing students' motivation to practice, and exercise the target language.

\section{Corrective Feedback and Achievement}

Besides motivation, corrective feedback has demonstrated marvellous effectiveness in augmenting pupils' achievement (Noureen \& Awan, 2013; Choi, 2013; Bitchener, 2008; Sheen, 2007; Bitchener, Cameron, \& Young, 2005; Bitchener \& Knoch, 2008). For instance, a study, which was launched at a secondary school in Pakistan, explored students' perceptions about the effects of corrective feedback on their achievements. Ahmed, Saeed, and Salam (2013) randomly selected three-hundred students to act as research participants in their study. Throughout the academic semester, pupils were provided with corrective feedback after any assignment. At the end of the year, the researchers administered a thirty item Likert-scale questionnaire to the research participants. After analyzing the data, the researchers stressed that $80 \%$ of the students agreed that corrective feedback improves their achievement, $75 \%$ asserted that corrective feedback is an essential facet of the teaching and learning processes, $84 \%$ believed that it enhances their self-esteem, $90 \%$ claimed that it must be employed in other subjects, $20 \%$ noted that it causes problems, and $42 \%$ insisted that tutors need to follow-up on the feedback, provided to them.

Also, Azizi, Behjat, and Sorahi (2014) probed the effects of corrective feedback on pupils' achievement at a school in Iran. They randomly picked sixty students to act as research participants and divided them into an experimental group, which received corrective feedback 
International Journal of Education (IJE) Vol.6, No.4, December 2018

after formative assessments and a control one, which received descriptive feedback. To elaborate, descriptive feedback is deemed as the process in which instructors provide learners with information in the form of comments. Accordingly, the initial assessment acted as a pretest and the last one acted as a posttest. Such assessments were graded using a precise rubric, which was designed by the researchers. After running the $t$-test and ANOVA, the researchers revealed that the experimental group outperformed the control group; therefore, it can be noted that corrective feedback positively impinges students' academic achievement.

Last, another study sought to trace the impact of corrective feedback on students' achievement at a school in Iran (Dehgani, Izadpanah, \& Shahnvaz, 2017). The researchers randomly picked three hundred students and divided them into an experimental group, which was provided with corrective feedback, and a control one, which received descriptive feedback. At the beginning of the semester, both groups sat for the pretest which was the school's speaking test. After six weeks, a posttest was administered for the two groups, and the school's speaking rubric was used to score both tests. After analyzing the data, the researchers attested that the experimental group outperformed the control group. Hence, corrective feedback has demonstrated remarkable effectiveness in upgrading students' academic achievement.

\section{Corrective Feedback and Performance}

In addition to motivation and achievement, corrective feedback has exhibited phenomenal effectiveness in augmenting students' performance (Anderson, 2010; Skinner, Shapiro, Turco, Cole, \& Brown, 1992; Jeon \& Kang, 2005; Ferris \& Roberts, 2001; Johnson, 1998; Heift, 2004; Buykbay, 2007; Havranek, 2002). For instance, Boudraa (2016) tested the impacts of corrective feedback on students' spelling performances at a school in Algeria. This study included seventy students, who were divided into an experimental group and control group. On the one hand, the experimental group received corrective feedback after any assessment or assignment. On the other hand, the control group was provided with descriptive feedback. A diagnostic test was used at the beginning of the semester to evaluate their spelling level, and a posttest was employed at the end of the semester to analyze the intervention's effectiveness. After running the $t$-test and ANOVA, Boudraa highlighted the fact that the experimental group outperformed the control group in the posttest.

Furthermore, Ebadi, Saad, and Abdelaziz (2010) assessed the impact of corrective feedback on English as Second Language (ESL) learners at a school in Turkey. The researchers randomly picked thirty students, who were divided into an experimental group and control group. To elaborate, the experimental group had been provided with corrective feedback, while the control group had not been provided with any feedback during the academic semester. At the beginning of the semester, a pretest was employed to test their levels in English grammar, and at the end of the semester, a posttest was used to evaluate the effectiveness of the intervention. After analyzing students' scores using the $t$-test and ANOVA, the researchers discovered that the experimental group's performance in grammar exceptionally outperformed the control group.

Finally, Atman and Mirici (2017) investigated the effects of corrective feedback on students' performance in writing at a school in Turkey. This study entailed sixty students, who were divided into a control group and experimental group. The control group did not receive any feedback on their assessments whereas the experimental group received corrective feedback. At the beginning of the academic semester, a diagnostic test was employed to assess their writing 
International Journal of Education (IJE) Vol.6, No.4, December 2018

skills, and at the end of the semester, a posttest was incorporated to evaluate the intervention's effectiveness. After analyzing the data, Atman and Mirici postulated that the performance of the experimental group was exceptional in the posttest in comparison to the control group. Besides, the researchers randomly selected nine pupils from the experimental group to explore their points of view about corrective feedback. Such participants highlighted that corrective feedback augmented their writing performance. Thus, corrective feedback has displayed outstanding effectiveness in enhancing ESL learners' performances.

On the contrary, Agudo (2012) accentuated the fact that corrective feedback affects learners' performance negatively. To further elaborate, he initiated a study at two secondary schools in Spain in order to examine the effect of corrective feedback on learners' performance. Also, he randomly picked eighty students, who participated in the study. At the end of the academic semester, Agudo administered a ten item Likert-scale questionnaire to the research participants. After analyzing the data, he accentuated the fact that $80 \%$ of the students regarded error making as an integral part of the learning process, $59 \%$ hated committing mistakes before their teachers, $77 \%$ deemed error correction as a vital part of the teaching process, $82 \%$ expected to be stopped and corrected by their teachers, $70 \%$ reported having a weak performance because of teachers' feedback, $20 \%$ felt humiliated when provided with feedback, $25 \%$ preferred to receive feedback in private for better understanding, $60 \%$ liked receiving feedback at the end of the class, $72 \%$ were fond of teachers' use of examples to elucidate their mistakes and $90 \%$ expected receiving thorough feedback from teachers. In conclusion, corrective feedback has been documented to negatively impinge learners' performances.

In addition to the above study, Belhadi (2013) investigated the impacts of corrective feedback on learners' performances. This study, which was initiated at a high school in Turkey, involved fourhundred students. Also, he employed a ten item Likert-scale questionnaire in an attempt to collect data from the participants. After analyzing the data, he highlighted that $95 \%$ of the students reported receiving regular feedback from their teachers, 54\% felt comfortable, and calm when receiving feedback, $70 \%$ admitted having a mediocre performance because of feedback, $68 \%$ confessed being discouraged to practice the target language due to teachers' feedback, $76 \%$ stressed on receiving feedback from their peers, $80 \%$ deemed feedback as a main part of the teaching process, $60 \%$ declared being undisturbed by their teachers' feedback, 33\% believed to be discouraged by their teachers' feedback, and $90 \%$ acknowledged the pivotal importance of feedback on their learning. Henceforth, learners' performance has been negatively impinged by corrective feedback.

\section{Research Gap}

After reviewing seven theses and twenty-seven research papers, it is observed that corrective feedback has exhibited staggering effectiveness in reinforcing the acquisition of English and Korean languages. Yet, the question of whether corrective feedback could corroborate identical effectiveness when employed in other foreign languages and various subject matters has to be thoroughly addressed. 
International Journal of Education (IJE) Vol.6, No.4, December 2018

\section{Recommendations}

When providing students with feedback, teachers must take into consideration important guidelines. First, teachers are advised by humanistic psychologists to be patient about students' errors (Dehgani, Izadpanah, \& Shahnavaz, 2017). Second, teachers need to be aware of the fact that feedback is a regular, cooperative, informative and descriptive procedure, not a delayed, judgmental and evaluative one (Hattie \& Timperley, 2007). Third, teachers need to focus on global mistakes, instead of local ones; the former refer to the ones, which distort the meaning, and sentence structure, whereas the latter refer to the ones, which do not pose a threat to the overall meaning (Mezhoud, 2015). Fourth, teachers need to help students set focused learning goals in an attempt to enhance their linguistic accuracy (Atman \& Mirici, 2017). Fifth, teachers need to be consistent so that students can successfully detect their learning gaps, spark their motivation, and improve their performance; however, "poorly done error correction will not help students and may mislead them in the future" (Gedye, 2010, p. 2). Sixth, teachers need to be aware of the fact that feedback serves as a basis for teaching; it draws their attention to the concepts, which have not been covered thoroughly and need to be re-visited. Seventh, teachers need to embed praise during feedback to instigate students' motivation and establish good relationships with them. Eight, teachers must familiarize learners with abbreviations employed during feedback. Last, teachers need to create a safe, learning environment where students rectify their errors without being anxious or frightened. In conclusion, these guidelines would empower teachers to provide effective feedback to their students.

\section{Conclusion and Further Research}

In conclusion, this paper has investigated the impacts of corrective feedback on ESL students' motivation, achievement and performance. To begin, corrective feedback is highlighted as a process in which teachers provide their students with feedback in regards to syntactic and lexical complexity, grammar and sentence structure. Besides, corrective feedback entails six, main categories, which are explicit, recast, explanation, metalinguistic, elicitation, and repetition. In addition, language acquisition is accentuated as the process of learning a second language. In an attempt to acquire a foreign language, learners automatically go through certain stages: preproduction, early production, speech emergence, intermediate stage and advanced stage. Moreover, corrective feedback has been documented to skyrocket students' motivation, and enthusiasm to acquire a second language. Also, corrective feedback has demonstrated notable effectiveness in increasing pupils' achievement. Lastly, corrective feedback has exhibited great effectiveness in augmenting learners' performance. However, other researches asserted that corrective feedback impinges learners' performance and motivation negatively. Finally, further researches need to be conducted to investigate the effectiveness of corrective feedback when being incorporated in other foreign languages and various subject matters.

\section{Biography}

The author graduated from Al-Alsun faculty, Ain Shams University in Cairo, Egypt. She is currently working as an English Intermediate Instructor at Zewail University. Last, she is enrolled in an M.A program (Educational leadership) at the American University in Cairo (AUC). 
International Journal of Education (IJE) Vol.6, No.4, December 2018

\section{References}

[1] Agudo, J. (2012). Investigating Spanish EFL students' beliefs and preferences regarding the effectiveness of corrective feedback. International Journal of Humanities and Social Science, 2(19), 121-131.

[2] Ahmad, I., Saeed, M., \& Salam, M. (2013). Effects of corrective feedback on academic achievements of students: Case of government secondary schools in Pakistan. International Journal of Science and Research, 2(1), 36-40.

[3] Anderson, T. (2010). The effects of tiered corrective feedback on second language academic writing. Retrieved from ProQuest Digital Dissertations.

[4] Ataman, D., \& Mirici, I. (2017). Contribution of corrective feedback to English language learners' writing skills development through workfolio based tasks. International Journal of Curriculum and Instruction, 9(1), 1-30.

[5] Azizi, M., Behjat, F., \& Sorahi, M. (2014). Effect of metalinguistic teacher corrective feedback on writing performance of Iranian EFL learners. International Journal of Language and Linguistics, 2(1), 54-63.

[6] Belhadi, K. (2013). The effect of teachers' corrective feedback on learners' oral fluency practice. Retrieved from ProQuest Digital Dissertations.

[7] Bitchener, J. (2008). Evidence in support of written corrective feedback. Journal of Second Language Writing, 7, $102-118$.

[8] Bitchener, J., \& Knoch, U. (2008). The value of a focused approach to written corrective feedback. ELT Journal, 63(3), 204-211.

[9] Bitchener, J., Young, S., \& Cameron, D. (2005). The effect of corrective feedback on ESL student writing. Journal of Second Language Writing, 14, 191-205.

[10] Boudraa, H. (2016). The effect of teacher's use of corrective feedback on EFL students' spelling performance. Retrieved from ProQuest Digital Dissertations.

[11] Buyukbay, S. (2007). The effectiveness of repetition as corrective feedback. Retrieved from ProQuest Digital Dissertations.

[12] Choi, S. (2013). The effects of written corrective feedback on second language writing focused on the English writing system. Retrieved from ProQuest Digital Dissertations.

[13] Chu, R. (2011). Effects of teacher's corrective feedback on accuracy in the oral English of Englishmajors college students. Theory and Practice in Language Studies, 1(5), 454-459.

[14] Dehgani, Q., Izadpanah, S., \& Shahnavaz, A. (2017). The effect of oral corrective feedback on beginner and low intermediate students' speaking achievement. Jordan Journal of Modern Languages and Literature, 9(3), 279-294. 
International Journal of Education (IJE) Vol.6, No.4, December 2018

[15] Ebadi, M., Saad, M., \& Abedalaziz, N. (2010). Corrective feedback and second language acquisition: Differential contributions of implicit and explicit knowledge. The Malaysian Online Journal of Educational Science, 2(2), 10-19.

[16] El Saghayer, M. (2014). Affective damage to corrective feedback among students in Libyan secondary schools. Journal of Research and Method in Education, 4(6), 74-82.

[17] Engin, A. O. (2009). Second language learning success and motivation. Social Behaviour and Personality, 37(8), 1035-1045.

[18] Ferris, D., \& Roberts, B. (2001). Error feedback in L2 writing classes: How explicit does it need to be? Journal of Second Language Writing, 10(3), 161-184.

[19] Gardner, R. (2011). Language learning motivation: The student, the teacher and the researcher. Foreign Language Education, 6(1), 1-18.

[20] Gedye, S. (2010). Formative assessment and feedback: A review. Planet, 23(1), 40-45.

[21] Hamidun, N., Hashim, S., \& Othman, N. (2012). Enhancing students' motivation by providing feedback on writing: The case of international students from Thailand. International Journal of Social Science and Humanity, 2(6), 591-594.

[22] Hattie, J., \& Timperley, H. (2007). The power of feedback. Review of Educational Research, 77(1), 81-112.

[23] Havranek, G. (2002). When is corrective feedback most likely to succeed? International Journal of Educational Research, 37(3), 255-270.

[24] Heift, T. (2004). Corrective feedback and learner uptake. TESOL Quarterly, 16(2), 416-431.

[25] Horbacauskiene, J., \& Kasperaviciene, R. (2015). Learners' preferences towards corrective feedback in writing assignments in tertiary education. Explorations in English Language and Linguistics, 3(2), 70-83.

[26] Jeon, M., \& Kang, I. (2005). Investigating student preferences in error correction in Korean-language teaching. The Korean Language in America, 10, 45-53.

[27] Johnson, P. (1988). English language and academic performance of undergraduate international students. TESOL Quarterly, 22, 164-168.

[28] Kuhl, P. K. (2004). Early language acquisition: Cracking the speech code. Nature Reviews Neuroscience, 5(11), 831-843.

[29] Leyla, A. (2016). The effectiveness of corrective feedback on motivation to improve students writing performance. Retrieved from ProQuest Digital Dissertations.

[30] Lo, J., \& Hyland, F. (2007). Enhancing students' engagement and motivation in writing: The case of primary students in Hong Kong. Journal of Second Language Writing, 16(4), 219-237.

[31] Mezhoud, M. (2015). The role of teachers' corrective feedback in motivating the EFL learners in the classroom. Retrieved from ProQuest Digital Dissertations. 
International Journal of Education (IJE) Vol.6, No.4, December 2018

[32] Nikolov, M., \& Djigunovic, J. M. (2006). Recent research on age, second language acquisition and early foreign language learning. Annual Review of Applied Linguistics, 26, 234-260.

[33] Noureen, G., \& Awan, R. (2013). Effect of descriptive Feedback and corrective feedback on academic achievement of VII graders in Mathematics. International Journal of Science and Research, $8(1), 20-40$.

[34] Owen, L. (2016). The impact of feedback as formative assessment on student performance. International Journal of Teaching and Learning in Higher Education, 28(2), 168-175.

[35] Pirhonen, N. (2016). Students' perceptions about the use of oral feedback in EFL classrooms. Retrieved from ProQuest Digital Dissertations.

[36] Sadler, R. (1989). Formative assessment and the design of instructional systems. Instructional Science, 18, 119-144.

[37] Sermsook, K., Liamnimitr, J., \& Pochak, R. (2017). The impact of teacher corrective feedback on EFL student writers' grammatical improvement. English Language Teaching, 10(10), 43-49.

[38] Sheen, Y. (2007). The effect of focused written corrective feedback and language aptitude on ESL learners' acquisition of articles. TESOL Quarterly, 41, 255 -283.

[39] Simpson, J. (2006). Feedback on writing: Changing EFL students' attitudes. TESL Canada Journal, 24(1), 96-112.

[40] Skinner, C., Sharpiro, E., Turco, T., Cole, C., \& Brown, K. (1992). A comparison of self-and peerdelivered immediate corrective feedback on multiplication performance. Journal of School Psychology, 30, 101-116.

[41] Stefansson, E. (2013). Second language acquisition: The effect of age and motivation. Annual Review of Applied Linguistics, 9, 1-30.

[42] UNESCO. (2016). Education. Retrieved from https://en.unesco.org/sdgs 